\title{
Reflecting on Experiential Learning in Marketing Education
}

\author{
Ross Brennan \\ Hertfordshire Business School \\ University of Hertfordshire \\ Hatfield
}

AL10 9AB

Email: d.r.brennan@herts.ac.uk

This is a preprint (pre peer-review) version of a paper submitted for consideration for the The Marketing Review, (c) Westburn Publishers Ltd, http://www.westburn.co.uk

\begin{abstract}
Experiential learning methods have become increasingly popular in marketing education. Factors underlying this trend are: the desire to respond to the changing higher education environment (the student-customer); to endow students with employability skills; the common sense assumption that since marketing is a practical activity learning from experience makes sense; and, pedagogic methods designed around experiential learning theory, which has been widely influential in recent decades. While not seeking to argue that experiential learning methods are ineffective in marketing education, this article argues that they should be used thoughtfully and where the learning goals and the cohort of students are likely to benefit from them. In particular, marketing educators should be wary of imposing an excessively high cognitive load on their students by expecting them to learn complex concepts from experiential learning methods that themselves have an intrinsically sharp learning curve, such as client consultancy projects.
\end{abstract}

\section{Keywords}

Marketing Education; Experiential Learning; Cognitive Load Theory. 


\section{Reflecting on experiential learning in marketing education}

\section{Introduction}

While marketing educators should always be encouraged to reflect on their pedagogic practices, now is a particularly opportune time to consider carefully the methods employed to educate marketing students. In the UK, changes in government higher educational policy have brought new pressures to bear upon universities, and these pressures are being felt and will be felt ever more keenly in university business schools. A number of related trends are important here: the increased 'sticker price' on a British university degree and the debt that graduates consequently assume; the associated, explicit move towards a more consumer-orientated approach to higher education and the notion of the student as a customer; the employability agenda, implying that universities carry considerable responsibility for preparing students for careers; and, the move towards increased competition in higher education. Business degrees, and marketing degrees in particular, feel the full force of the pressures arising from these trends. Under these circumstances, it is important to be able to justify the pedagogic methods employed on marketing courses. Justification means making the best use of the available research evidence when choosing pedagogic approaches. Using this perspective, this article critically examines the place of experiential learning in the university marketing curriculum.

In summary, the argument of this article is in three parts. First, the proposition is developed that experiential learning methods are frequently employed on marketing courses and that such methods are either justified implicitly (based presumably on the assumption that since marketing is a practical activity it follows that practical learning methods must be best) or, commonly, are justified on the basis of the experiential learning theories of David Kolb.

Second, recent studies in marketing education are described that suggest that, in practice, experiential learning methods may not always be as successful as hoped. Third, an exploration of the learning theories that underpin experiential learning (and other so-called minimal guidance approaches to education) suggests that there are good reasons why such methods may be less effective than expected. The purpose of the article is certainly not to persuade marketing educators to eliminate experiential learning from their practice; rather it is to focus attention on the potential weaknesses in experiential learning so that such methods can be employed to best effect and only where appropriate.

The use of experiential methods as a default approach to marketing education, without careful consideration and integration of the underlying theories of experiential learning, could lead to a superficial learning experience. This article evaluates the risks of this outcome and alerts marketing educators to the risks. The paper begins with a summary of 
recent research into experiential learning in marketing education, from which certain reservations about the use of experiential methods are derived. It is proposed that these reservations may partly be explained by inadequate absorption of the underlying principles of experiential learning into the design of learning activities in marketing, so the subsequent section briefly addresses the origins and principles of experiential learning. The concluding section of the paper offers analysis and advice for marketing educators who are concerned to ground their experiential learning projects more soundly in educational theory.

\section{Experiential learning in marketing education}

A substantial body of published research exists dealing with the use of experiential learning on university-level marketing education courses. One recent definition of experiential learning from an article about marketing education is "effective learning resulting from active student involvement with an experience and subsequent reflection on that experience" (Camarero, Rodriguez, \& San José, 2010:84). Techniques of experiential learning have been extensively used and studied in the context of marketing education, and constitute one of the most thoroughly investigated topics in marketing education research (Gray, Peltier, \& Schibrowsky, 2012). Experiential learning has long been a subject of interest to marketing educators. The subject was addressed by Marcus in the very first issue of the Journal of Marketing Education (Marcus, 1979). More recently, in a review of everything published in the Journal of Marketing Education between its launch in 1979 and 2012, Gray, Peltier and Scibrowsky (2012) found that experiential learning was the second most popular topic and accounted for $15.1 \%$ of the articles published in the journal (121 out of a total of 802 articles). With regard to experiential learning Gray, Peltier and Scibrowsky (2012: 233) remarked: "Experiential Learning is a cornerstone of marketing education and a signature pedagogy for the discipline. Although experiential learning exercises have changed over time, offering real-world educational experiences are (sic) vital for preparing students to compete in an ever-changing and increasingly competitive job market." Published articles researching the effectiveness of experiential learning, describing experiential learning methods and offering advice to marketing educators interested in adopting experiential learning techniques have also featured in the other principal journals in the field, the Marketing Education Review and the Journal for the Advancement of Marketing Education (Examples: Greene, 2011; Pollack \& Lilly, 2008; Young, Caudill, \& Murphy, 2008); in management education journals (Examples: Brennan \& Pearce, 2009; Camarero et al., 2010); and occasionally in general marketing journals particularly where a special issue is devoted to marketing education (Examples: Ardley \& Taylor, 2010; Harker \& Brennan, 2003).

Where marketing educators and researchers mention underlying theories of learning upon which their experiential techniques are based, they refer most often to Kolb's experiential learning theory (D. A. Kolb, 1984). Ardley \& Taylor (2010) also cite the literature on tacit knowledge, arguing that where experiential learning involves real-world projects students have the opportunity to learn tacit knowledge that would otherwise be inaccessible to them. However, one also gets the sense from reading this literature that some marketing 
educators regard it as a self-evident that learning through experience is desirable, and that additional justification from theories of learning is not entirely necessary. For example, Ganesh \& Qin (2009) adopt a largely atheoretical approach to experiential learning, justifying an experience-based approach mainly with the assertion that today's studentsthe Millennials - expect and need highly engaging experiential learning methods and respond poorly to didactic approaches. In summary, marketing educators have used three principal arguments to justify the use of experiential learning: the often implicit, atheoretical argument that marketing is a practical field so that practical learning is required to prepare students for marketing careers; the explicit argument that students, particularly Millennials, find such methods interesting and engaging the interest of students is important; and, the explicit argument that active learning approaches, notably experiential learning, can be justified by recourse to learning theory, with Kolb's learning cycle the most frequently cited learning model. In these arguments one can readily find echoes of the trends in higher education policy mentioned in the opening paragraph. Arguments brought to bear in favour of experiential learning include employability, the student as customer, and increased competition among higher education institutions. As we will see, however, contradictions can arise. What happens, for example, if experiential methods designed by marketing educators to enrich the student learning experience and enhance their employability, are found to be unattractive for one reason or another by the studentcustomer? Some recent research has suggested that such a dilemma is far from merely a hypothetical possibility.

Many of the published studies of experiential learning in marketing education follow a similar pattern: support for experiential learning is sought from educational theory; the authors describe their implementation of a particular experiential learning method; data (qualitative, quantitative, or both) are gathered from the participating students; and, the efficacy of the method is shown to be high. The measures used, although varying in detail, tend to concentrate on student satisfaction with the learning process, and student selfreports about how much they believe they learned (perhaps inviting them to mentally compare the experiential exercise with didactic approaches). Experiential learning techniques studied this way include: computer-based sales/marketing simulation games (Bobot, 2010; Ganesh \& Qin, 2009; Vos \& Brennan, 2010); live marketing projects conducted by students on behalf of real-world businesses (Ardley \& Taylor, 2010; Camarero et al., 2010; Inks, Schetzle, \& Avila, 2011); and, the development by students of realistic marketing plans for the launch of a new, viable business venture (Camarero et al., 2010). The evaluation of the learning achieved by the students as a result of participation in the experiential learning activity can be fairly cursory. For example, Inks et al (2011) describe at some length a practical, real-world sales task undertaken by students as a component of their marketing course; they draw upon Kolb's experiential learning approach for theoretical justification. However, very little information is provided concerning the evaluation of the learning method. Although Inks et al (2011: 41) assert that: "The impact of this experiential project on student learning is tremendous", the only evidence they cite for this proposition is "anecdotal evidence" (p42).

Many of the articles describing experiential learning approaches in marketing education are both fascinating and inspirational. However, reports of such studies often suggest that enthusiasts with a passion for the approach to learning described in the article were responsible for the course design, the research design, data gathering, analysis and 
reporting of the results (self-disclosure: the author writes as someone who has done exactly that). Without in any way wishing to suggest any explicit bias in these research studies, nevertheless one wonders whether neutral research undertaken by disinterested parties would have arrived at equally positive conclusions. In addition, while the wider curriculum context for the study is not often described, the reader gathers from many of these articles that the authors perceive their own course to be innovative and relatively unusual. This suggests two important questions: first, whether these methods would be equally successful when implemented as a routine part of the curriculum by educators with no specific enthusiasm for the approach; and, second, whether such approaches to learning would be equally successful if they were widely implemented and simply became the normal way that marketing is taught. Consequently, while much of the prior research into experiential learning methods in marketing education is interesting, it does not represent serious evidence demonstrating the superiority of one experiential method over another, or of experiential methods in general over other learning approaches. There is very little evidence at all addressing the proposition that experiential learning methods are a better way of achieving certain learning outcomes than conventional methods; nor is there evidence that experiential methods make certain learning outcomes achievable which would not be achievable using conventional methods. Much of the literature in this field has an evangelical feel to it. There is a dearth of well-designed scientific studies in marketing education seeking to demonstrate the objective differences in effectiveness between learning approaches, still less is there a body of evidence demonstrating the superiority of experiential methods over conventional methods.

\section{Cautionary evidence from marketing educators}

Some recent articles have suggested that a more critical approach towards experiential learning is required in the field of marketing education. Young et al (2008) studied a university Principles of Marketing course on which experiential learning methods were implemented; they measured the extent to which the students engaged with the four stages of the Kolb learning cycle (concrete experience; reflective observation; abstract conceptualisation; active experimentation), whether students used a deep or a surface approach to learning, and student perceived learning. Analysis by Young et al (2008) shows that, unless students are guided through all four stages of the Kolb learning cycle, experiential learning activities can result in surface learning rather than deep learning. It is concluded that experiential learning techniques are not a panacea, but a tool that has to be incorporated carefully into the learning process if the desired results (such as student critical engagement and deep learning) are to be achieved.

Hunter-Jones (2012) describes a real-world, client-based project to develop a marketing strategy for an independent preparatory school that she developed for final year undergraduate students. Before implementing it, she conducted a focus group to seek the views of some of the students who could choose this optional module:

"All were final year learners and were able to select the course as an option. An outline of the project was given and the opportunities it presented to develop skills, research skills particularly, which could be transferable within different work-based contexts outlined. 
There was some uncomfortable shuffling around and then one learner commented "to be honest we're not that interested ... we just want to achieve the best marks possible ... is this going to be possible, or would you suggest taking a course with a normal assignment?"'” (Hunter-Jones, 2012:24)

Hunter-Jones emphasises that it was not poorly qualified, disengaged students who expressed such attitudes, but students who had previously been successful and who wanted nothing to stand in the way of achieving further high grades-she calls them "formulaic learners", who "are less prepared, or even able, to be flexible and accommodating of other learners in case this has a negative influence on their overall mark. They want to be in control of their own achievements and are formulaic in achieving this"(Hunter-Jones, 2012:26). Formulaic learners are very capable students who have been through a highly structured learning process at school, and have learned how to be successful within such a learning process. Rather than embracing the excitement and uncertainty of an experiential learning assignment they feel threatened, and may avoid optional courses that involve such experiences. An interesting parallel to the work of Hunter-Jones (2012) can be found in Ackerman and $\mathrm{Hu}$ (2011), who used the learning orientations methodology of Martinez (2001) to measure differences in response to learning approaches between students with high and low learning autonomy. Students with high autonomy were found to respond positively to active learning approaches, while students with low autonomy were less favourably disposed towards active learning. Certainly, both Hunter-Jones (2012) and Ackerman and $\mathrm{Hu}$ (2011) provide evidence against the proposition that active and experiential learning methods are always appropriate in marketing education. As Ackerman and $\mathrm{Hu}$ (2011:281) contend: "active learning assignments are not the universal key to success for everyone to learn in a marketing class."

Two key issues emerge from the work of Hunter-Jones (2012) and of Young et al (2008). First, that there may be growing resistance to experiential learning methods from undergraduate students who have become used to a strongly assessment-driven mode of education at secondary school level. The central proposition is that such students experience negative affect because of the uncertainty they perceive to be associated with the learning and assessment processes of experiential methods; a subsidiary proposition is that students will seek to avoid experiential learning and will choose conventional methods where a choice is available. In simple terms, Hunter-Jones' work suggest that there are able students who will seek to evade the efforts of marketing educators to engage them in experiential learning exercises, and who prefer to learn and then be assessed on a body of explicit knowledge. The second key issue is that experiential methods in marketing education may not lead to deep learning because the experience is not converted into genuine experiential learning through such processes as reflection and re-conceptualisation. Simply put: "experience in and of itself is not educative ... if students do not think seriously about their experiences, their experiences may reinforce stereotypes and incorrect suppositions" (Young et al., 2008:28). 


\section{Experiential learning: back to basics}

Clearly, the successful implementation of experiential learning into the marketing curriculum is more than a matter of providing students with either real or simulated marketing experiences. This seems like a suitable moment for marketing educators to reconsider the basics of experiential learning. Experiential methods, once innovative and unusual, may have become such an automatic part of the marketing curriculum that they are considered routine. However, evidence is emerging that certain difficulties are emerging with the application of experiential learning. Perhaps a re-examination of the fundamental principles of experiential learning will cast light on the source of these difficulties.

Probably the best-known contemporary theorist of experiential learning, David Kolb, traces the roots of experiential learning to John Dewey. Dewey conceived of education as the most fundamental aspect of human society; without education society would be unable to reproduce itself, and experience is considered to be fundamental to learning (Dewey, 1938). Kolb defines experiential learning as: "the process whereby knowledge is created through the transformation of experience" (D. A. Kolb, 1984:38). Kolb's experiential learning theory (ELT), based on the ideas of Dewey and other twentieth century scholars (such as Lewin, Piaget and Jung) is built on the six propositions illustrated in Table 1 (Kolb and Kolb 2005).

Table 1: Principles of Experiential Learning Theory

\begin{tabular}{|l|l|}
\hline 1. & Learning is best conceived as a process, not in terms of outcomes. \\
\hline 2. & $\begin{array}{l}\text { All learning is relearning; drawing out students' beliefs and ideas about a topic so } \\
\text { that they can be examined and integrated with new, more refined ideas. }\end{array}$ \\
\hline 3. & $\begin{array}{l}\text { Learning requires the resolution of conflicts between dialectically opposed modes } \\
\text { of adaptation to the world; reflection/action, and feeling/thinking. }\end{array}$ \\
\hline 4. & $\begin{array}{l}\text { Learning is a holistic process of adaptation to the world; cognition, feeling, } \\
\text { perceiving, behaving. }\end{array}$ \\
\hline 5. & $\begin{array}{l}\text { Learning results from synergetic transactions between the person and the } \\
\text { environment. }\end{array}$ \\
\hline 6. & Learning is the process of creating knowledge. \\
\hline
\end{tabular}

(Sources: A. Y. Kolb \& Kolb, 2005; D. A. Kolb, 1984)

The difficulties associated with applying ELT to marketing education, certainly in contemporary British universities, perhaps start with point 1 in Table 1. Recent debate in the Times Higher has highlighted the ubiquity of learning outcomes in British universities, the considerable store that university managers set by them, and the distaste with which they are regarded by many academic staff (Furedi, 2012). Certain other aspects of ELT, as summarised in Table 1, also give pause for thought in the context of teaching marketing in higher education. For example, does it make sense to suppose that learning is "relearning" under these circumstances? No doubt many marketing educators would consider that they are trying to convey an entirely new body of knowledge, and an entirely new way of 
thinking to their students. In addition, what proportion of marketing educators would agree that "learning is the process of creating knowledge", and what proportion would agree more with what Kolb and Kolb (2005) call the transmission model-the opposite of experiential learning-where pre-existing fixed ideas are transmitted to the learner?

\section{Critiques of experiential learning theory}

Kolb's theory of experiential learning, while given pride of place in many management textbooks, is (along with other minimal guidance learning methods) the subject of intense controversy in the field of educational psychology. It is important to point out that this paradigm of education has been the subject of considerable criticism from educational researchers: a good summary of the main debates, considering both criticisms and counterarguments from ELT proponents is provided by Kayes' (2002). A particular criticism levelled at ELT and other, similar, methods of "instruction using minimal guidance" is that, firstly, the structure of human cognitive architecture is now sufficiently well understood to render the claims of ELT dubious, and that, secondly, the weight of empirical evidence from a large number of studies suggests that minimal guidance methods are neither efficient nor effective learning techniques (Kirschner, Sweller, \& Clark, 2006).

Kirschner et al (2006) argue that whereas direct instructional guidance methods provide information that fully explains the concepts and procedures that students are required to learn, minimal guidance techniques challenge students to learn by solving 'authentic' problems in information-rich settings on the assumption that by constructing their own solutions students will have the most effective learning experience. Experiential learning is in the category of minimal guidance techniques, alongside such methods as problem-based learning, inquiry learning, and constructivist learning. Such methods assume that "knowledge can best be acquired through experience based on the procedures of the discipline" (Kirschner et al 2006:76). Students are offered minimal guidance, so that processand task-related information is available to them only should they choose to use it. The two prongs of the critique are, first, that contemporary understanding of human cognitive architecture renders it unlikely that minimal guidance techniques will be effective, and, second, that the evidence from a large number of empirical studies has failed to show that minimal guidance methods are effective and tends to suggest that they are relatively ineffective.

Concerning the structure of human cognitive architecture, the principal contention is that learning can be defined as a change in long-term memory, and that for long-term learning to take place information must first be processed through short-term memory (working memory). Kirschner et al (2006:77) make the following important assertion: "The aim of all instruction is to alter long-term memory. If nothing has changed in long-term memory, nothing has been learned." However, learning from minimally guided experiential learning tasks relies on information being passed to the long-term memory from the working memory at a time when the individual is engaged in a complex task which imposes a substantial cognitive burden-a process which current knowledge of human cognitive 
architecture considers to be very inefficient (Kirschner et al., 2006). The capacity of working memory to process new information is low, and the ability to transfer new information from working memory to long-term memory is limited. Under the cognitive load imposed by typical minimal guidance methods, such as experiential learning, it is to be expected that the process of building long-term memory from novel information in working memory would be severely constrained. Consequently, argue Kirschner et al (2000), minimal guidance methods are unlikely to be vehicles for effective learning; there is an incompatibility between minimally guided instruction and what is known about human cognitive architecture. This argument falls within the general terms of cognitive load theory (Paas, Renkl \& Sweller 2004), which suggest that the design of learning activities should take account of the cognitive load imposed on learners because at very high (and very low) levels of cognitive load learning is ineffective. In complex experiential learning activities the risk arises of a considerable 'extraneous load', that is to say, cognitive load that does not contribute to the learning experience. This is a matter of particular concern with novice learners, "who lack proper schemas to integrate the new information with their prior knowledge" (Moreno 2004:100).

As Kirschner et al (2000) observe, arguments about learning effectiveness based on analysis of the structure of human cognition would be neither here nor there if there was overwhelming empirical evidence demonstrating that minimal guidance instruction methods do, in fact, work. They assert that although many studies have been carried out, no such evidence exists. For example, Mayer (2004) reviewed the evidence for 'discovery learning' approaches in empirical studies since 1960, and concluded that 'pure discovery' is the least effective learning approach, while 'guided discovery' is much more effective. Mayer's conclusion is that learning approaches that emphasise behaviour, while deemphasising cognitive engagement, are ineffective. Learners should not simply be left adrift in a problem-solving situation, but should be provided with guidance towards the knowledge frameworks that are the desired outcome from the learning experience: "The debate about discovery has been replayed many times in education, but each time, the research evidence has favored a guided approach to learning" (Mayer 2004: 18). In an experiment investigating the comparative effectiveness of discovery learning and direct instruction methods to teach science to school age children, Klahr and Nigam (2004) found that direct instruction was clearly superior to discovery learning as an instructional method. In Klahr and Nigam's (2004) experiment, those who attained mastery of the subject were equally capable of applying the knowledge they had learned, regardless of whether they learned this through discovery learning or direct instruction; the discovery learning approach did not endow learners with an enhanced ability to apply knowledge. Similar findings, of the superiority of strongly guided instruction over discovery learning, emerged from Moreno's (2004) experimental study undertaken with university psychology students.

On the basis of their review of the empirical studies addressing the relative effectiveness of minimal guidance methods, Kirschner et al (2006:83) conclude that: "After a half-century of advocacy associated with instruction using minimal guidance, it appears that there is no body of research supporting the technique. In so far as there is any evidence from controlled studies, it almost uniformly supports direct, strong instructional guidance rather than constructivist-based minimal guidance during the instruction of novice to intermediate 
learners."

This point of view has, however, been challenged in the educational psychology literature (Hmelo-Silver, Duncan, \& Chinn, 2007). Furthermore, Kolb and Kolb (2005) support their own arguments in favour of ELT with reference to work in neuroscience that suggests that the process of experiential learning is related to the process of brain functioning (Zull, 2002). Clearly, the debate about the fundamental educational merits of ELT is a continuing one.

\section{Conclusion and suggestions for further research}

Considerable research evidence exists about experiential learning, both within marketing education and in a wide range of other contexts. The principal conclusion that arises from evaluating this evidence is that marketing educators cannot make a clear and unambiguous presumption in favour of experiential learning. This area of educational theory is contested. The ambiguity in wider evidence and wider debates about the efficacy of experiential learning is also apparent within the marketing academy. Some researchers strongly advocate experiential methods, often with supporting empirical evidence, but usually only with evidence that is compromised in some rather obvious way (for example, student selfreports of increased understanding rather than objective test evidence, small-scale single institution studies, researchers who are advocates for their particular learning method rather than disinterested parties). There are also studies within marketing education that throw doubt on the usefulness of experiential learning. One very important message, however, is that experience is not the same thing as experiential learning; simply providing students with real-life or simulated experiences of marketing activities is not sufficient to generate experiential learning.

Marketing educators may find that the conditions necessary for successful experiential learning are at odds with wider educational trends that affect policies at their own universities. Experiential learning is holistic and process-orientated, and so may be incompatible with educational policies that are reductionist, purely outcome-orientated, and predominantly instrumental. Attempts to use genuine experiential learning methods in institutions where learning policy is narrowly assessment-driven and learning-outcome focused are likely to prove problematic.

A number of areas for further research suggest themselves. There appear to be contrary reports concerning the learning orientation of the Millennial generation; Ganesh and Qin (2009) report that members of this generation prefer experience-orientated learning methods, while Hunter-Jones (2012) reports that at least some of them are instrumental, and suspicious of experiential learning methods because of the unpredictable assessment outcomes. Several explanations may account for these different observations (for example: one was an American study, the other was a British study; one concerned a simulation game, the other a client-based student project). Certainly there is room for further investigation here. Other research questions not yet answered in the literature concern the 
routinisation of experiential learning methods, and their delivery by educators who are nonenthusiasts. What happens when experiential learning methods become a standard part of the marketing curriculum and are delivered by staff with no particular interest in the learning technique?

\section{References}

Ackerman, David S., \& Hu, Jing. (2011). Effect of Type of Curriculum on Educational Outcomes and Motivation Among Marketing Students With Different Learning Styles. Journal of Marketing Education, 33(3), 273-284. doi: 10.1177/0273475311420233

Ardley, Barry, \& Taylor, Nick. (2010). The student practitioner: Developing skills through the marketing research consultancy project. Marketing Intelligence \& Planning, 28(7), 847-861.

Bobot, Lionel. (2010). Teaching Sales and Negotiation with Combining Computer-Based Simulation and Case Discussions. Marketing Education Review, 20(2), 115-122.

Brennan, Ross, \& Pearce, Glenn. (2009). Educational Drama: A Tool for Promoting Marketing Learning? International Journal of Management Education, 8(1), 1-10.

Camarero, Carmen, Rodriguez, Javier, \& San José, Rebecca. (2010). A Comparison of the Learning Effectiveness of Live Cases and Classroom Projects. International Journal of Management Education, 8(3), 83-94.

Dewey, John. (1938). Education and experience. New York: Simon and Schuster.

Furedi, Frank. (2012, 29 November). The unhappiness principle, Times Higher, pp. 34-39.

Ganesh, Gopala, \& Qin, Sun. (2009). Using Simulations in the Undergraduate Marketing Capstone Case Course. Marketing Education Review, 19(1), 7-16.

Gray, Deborah M., Peltier, James W., \& Schibrowsky, John A. (2012). The Journal of Marketing Education : Past, Present, and Future. Journal of Marketing Education, 34(3), 217-237. doi: $10.1177 / 0273475312458676$

Greene, Henry. (2011). Freshmen Marketing: A First-Year Experience with Experiential Learning. Marketing Education Review, 21(1), 79-88.

Harker, Michael, \& Brennan, Ross. (2003). E-marketing action: an action learning approach to teaching e-marketing. The Marketing Review, 3(4), 419-432.

Hmelo-Silver, Cindy E., Duncan, Ravit Golan, \& Chinn, Clark A. (2007). Scaffolding and Achievement in Problem-Based and Inquiry Learning: A Response to Kirschner, Sweller, and Clark (2006). Educational Psychologist, 42(2), 99-107. doi: 10.1080/00461520701263368

Hunter-Jones, Philippa. (2012). The Continuum of Learner Disengagement: Ethnographic Insights into Experiential Learning in Marketing Education. Journal of Marketing Education, 34(1), 1929. doi: $10.1177 / 0273475311430801$

Inks, Scott, Schetzle, Stacey, \& Avila, Ramon. (2011). Taking the Professional Sales Student to the Field for Experiential Learning. Journal for Advancement of Marketing Education, 19(1), 3547.

Kayes, Christopher D. (2002). Experiential Learning and its Critics: Preserving the Role of Experience in Management Learning and Education. Academy of Management Learning \& Education, 1(2), 137-149.

Kirschner, Paul A., Sweller, John, \& Clark, Richard E. (2006). Why Minimal Guidance During Instruction Does Not Work: An Analysis of the Failure of Constructivist, Discovery, ProblemBased, Experiential, and Inquiry-Based Teaching. Educational Psychologist, 41(2), 75-86. doi: $10.1207 /$ s15326985ep4102_1

Kolb, Alice Y., \& Kolb, David A. (2005). Learning Styles and Learning Spaces: Enhancing Experiential Learning in Higher Education. Academy of Management Learning \& Education, 4(2), 193212.

Kolb, David A. (1984). Experiential Learning: Experience as the Source of Learning and Development. Englewood Cliffs, NJ: Prentice Hall. 
Marcus, Burton H. (1979). Experiential Learning in Marketing: Synthesis and Action for a Capstone Course. Journal of Marketing Education, 1(1), 13-18. doi: 10.1177/027347537900100104

Martinez, Margaret. (2001). Mass Customization: Designing for Successful Learning. International Journal of Educational Technology, 2(2).

Pollack, Birgit Leisen, \& Lilly, Bryan. (2008). Gaining Confidence and Competence through Experiential Assignments: An Exploration of Student Self-Efficacy and Spectrum of Inquiry. Marketing Education Review, 18(2), 55-66.

Vos, Lynn, \& Brennan, Ross. (2010). Marketing simulation games: student and lecturer perspectives. Marketing Intelligence \& Planning, 28(7), 882-897.

Young, Mark R., Caudill, Eve M., \& Murphy, J. William. (2008). Evaluating Experiential Learning Activities. Journal for Advancement of Marketing Education, 13, 28-40.

Zull, James, E. (2002). The Art of Changing the Brain: Enriching Teaching by Exploring the Biology of Learning. VA: Stylus: Sterling. 